InterAção | 161

\title{
O RECONHECIMENTO DA REPÚBLICA POPULAR DA CHINA E O PRAGMATISMO RESPONSÁVEL FATORES DOMÉSTICOS E EXTERNOS
}

\author{
Dimitri Silva Nunes de Oliveira* \\ Rômulo Barizon Pitt**
}

Resumo

O presente artigo revisa o papel e os fatores envolvidos no reatrelamento diplomático do governo brasileiro com a China continental em 1974, no âmbito do "pragmatismo responsável”. O pragmatismo responsável da presidência do general Geisel e a decisão de reconhecer a China comunista se explicam em grande parte pelas circunstâncias favoráveis no cenário internacional de então, que exigia o reposicionamento brasileiro. Entretanto, é a dinâmica política doméstica dos dois países, mais criticamente do Brasil, que permitem, em última instância, a aproximação entre os dois governos.

\section{Abstract}

This article reviews the role and the factors involved in the

\footnotetext{
* Dimitri Silva Nunes de Oliveira é graduando no curso de Relações Internacionais pela Universidade Federal do Rio Grande do Sul, pesquisador no IFCH (Departamento de História). ** Rômulo Barizon Pitt é graduando no curso de Relações Internacionais pela Universidade Federal do Rio Grande do Sul, pesquisador no NERINT (Núcleo de Estratégia e Relações Internacionais).
} 
diplomatic rapprochement between the Brazilian government, under the "responsible pragmatism", and mainland China, in 1974. General Geisel's pragmatism and the decision to recognize Communist China can be largely explained by favorable circumstances in the international arena, which demanded a repositioning on the part of Brazil. However, it is the domestic political dynamics of the two countries, Brazil's most critically, that allow, ultimately, the rapprochement between the two governments.

\section{INTRODUÇÃO}

O reconhecimento da República Popular da China (RPC) constituiu um marco na política externa dos governos militares e da história diplomática brasileira. Em clara oposição à linha externa adotada pelos governos predecessores, o governo Geisel relegou menor importância ao peso da ideologia nas iniciativas de política externa brasileiras, no contexto da política externa que ficou conhecida como "pragmatismo responsável”.

De certa forma, como contrapartida da liberalização política interna, a liberalização da política externa ganhou força com o general Geisel, militar reconhecido por pertencer às alas moderadas do regime que ascendeu ao poder em 1964. A liberalização da política internacional, no primeiro momento, assumiu forma em três principais iniciativas: a mudança de posição no conflito árabe-israelense em prol das nações árabes, o apoio à descolonização portuguesa na África e o reatrelamento de relações diplomáticas com a RPC. Em comum com a contrapartida interna, a liberalização nas relações exteriores foi colocada em prática de 
InterAção | 163

forma "gradual e segura", muito embora se perceba que no cenário internacional tal iniciativa foi mais veloz que a redemocratização doméstica.

Dada a importância e, principalmente, a representatividade do evento do reconhecimento da RPC para a política externa brasileira, encontra-se no Brasil extenso trabalho acadêmico acerca deste evento, seu papel e seus condicionantes. Assim, este artigo buscará condensar os fatores internos e externos referentes aos dois países e a dinâmica entre estes diferentes aspectos no que condiz à aproximação entre os dois governos. Apesar das marcadas diferenças ideológicas entre os regimes, as mudanças no sistema internacional, assim como as mudanças na dinâmica política dentro das arenas decisórias dos dois países, acabaram por reverter o processo de afastamento que se vislumbrava desde o início do governo Castello Branco.

A partir desta constatação, elencamos como hipótese que tanto as mudanças externas quanto as internas de ambos os países configuram pré-requisitos sem os quais não haveria a aproximação no momento em que se deu - provavelmente a aproximação diplomática só se daria mais tarde sem tal conjunto de fatores. $\mathrm{Na}$ análise da arena política doméstica brasileira, o presente artigo se baseou principalmente no estudo de HIRST (1984). A partir de uma revisão bibliográfica, será avaliado o diálogo entre os principais atores envolvidos nas relações bilaterais Brasil-RPC durante o governo Geisel e seu "pragmatismo responsável”.

\section{Contextualização}

O fim do governo Médici foi marcado por uma intensa crise econômica no Brasil e no mundo. No ano de 1973 estourou a crise do 
petróleo, orquestrada pela OPEP como sinal de protesto ao apoio dos Estados Unidos a Israel na Guerra do Yom Kippur. O preço do petróleo teve um aumento vertiginoso, impactando a economia mundial e especialmente a brasileira. Isso se deve pelo fato de que o Brasil na época era o maior importador de óleo entre os países em desenvolvimento e o sétimo em escala mundial, o que fez com que o país passasse a gastar cerca de $40 \%$ de sua receita adquirida em exportações com a importação desse insumo, em 1974. Para efeito de comparação, o mesmo percentual, em 1972, girava em torno de 15\% (BREDA DOS SANTOS, 2000).

O choque do petróleo causou forte recessão nos países industrializados, tradicionais importadores de produtos brasileiros e investidores externos na economia nacional. Assim, o modelo de desenvolvimento escolhido pelo Brasil, que "empregava energia importada barata, dependia do afluxo de investimentos de capitais estrangeiros e da utilização de tecnologia também importada" (VIZENTINI, 1998), sofreu forte revés. Em suma, a crise do petróleo inverteu toda a conjuntura próspera que propiciou o rápido crescimento entre os anos de 1968 e 1973. A situação se torna mais drástica se levarmos em conta a opção do governo brasileiro pelo transporte rodoviário em detrimento do ferroviário e hidroviário, feita como parte da estratégia para a atração e instalação de indústrias automobilísticas internacionais no país. $\mathrm{O}$ aumento do número de automóveis e a consequente necessidade de aumentar a importação de petróleo intensificavam ainda mais a derioração das contas externas nacionais.

Mesmo antes do choque do petróleo, o sistema econômico internacional já apresentava sinais de mau desempenho. Em boa par- 
te como efeito da administração Nixon e do baixo desempenho da economia norte americana, atrelada aos custos da guerra na Indochina, o quadro internacional era de recessão e de exacerbação do protecionismo. $\mathrm{O}$ protecionismo era proveniente principalmente das nações desenvolvidas, as quais ocupavam posição de destaque na pauta de comércio exterior do Brasil, enquanto que setorialmente afetavam diretamente as economias exportadoras de produtos primários - o que agravava as perdas brasileiras.

Destarte, o "milagre econômico" dava sinais visíveis de esgotamento, elimando assim um dos principais pilares de sustentação do governo militar. A discussão sobre abertura política crescia cada dia com mais força no seio da sociedade e a explosão da radicalização se mostrava como uma perspectiva real e próxima. Concomitantemente, existiam confrontos internos no governo, onde linha dura e moderada não conseguiam articular uma postura única e eficaz para reverter o quadro da economia nacional. O cenário conjuntural demandava uma mudança de postura do governo, cuja legitimidade passava a ser questionada.

Em março de 1974 assumiu a presidência da República Ernesto Geisel, militar da linha moderada, com a responsabilidade de arrefecer a crise interna e permitir que o processo de abertura se desse de forma "lenta, gradual e segura". Uma de suas primeiras ações nesse sentido foi mudar o rumo da política externa, inaugurando o período conhecido como "pragmatismo responsável" da diplomacia nacional. Nas palavras de Geisel:

"[...] a política externa (a ser adotada) tinha que ser realista e, tanto quanto possível, independente. Andávamos demasiadamente a reboque dos Estados 
166 | InterAção

Unidos. Sei que a política americana nos levava a isso, mas tínhamos que ter um pouco mais de soberania, um pouco mais de independência, e não sermos subservientes em relação aos Estados Unidos. [...] Nossa política tinha que ser pragmática, mas também responsável. O que fizéssemos tinha que ser feito com convicção e no interesse do Brasil, sem dubiedades." (D'ARAUJO \& CASTRO, 1996, p. 336)

Comparando-a com a política adotada pelo governo de Castello Branco, nota-se um contraste significativo, principalmente quanto ao relacionamento entre Brasil e Estados Unidos. Entre os anos de 1964 e 1967, a proposta vigente era a de "desmantelar os princípios que regiam a Política Externa Independente, tais como o nacionalismo, base da industrialização brasileira, o ideário da Operação Pan-Americana e a autonomia do Brasil em face da divisão bipolar do mundo e da hegemonia norte-americana sobre a América Latina" (MALAN, 1984). Em outras palavras, o objetivo central da política castellista era retificar o "curso sinuoso" apresentado pela política externa dos governos de Jânio Quadros e João Goulart, pois se acreditava que a política neutralista até então defendida não servia aos propósitos de um país como o Brasil. A tese da segurança coletiva $^{1}$ e o incremento das relações entre Brasil e Estados Unidos no período foram consequências naturais da nova linha adotada pelo Itamaraty. Durante os governos de Costa e Silva e Médici, houve uma atenuação na ênfase da identificação ideológica com o bloco políti-

$1 \mathrm{~A}$ tese da segurança coletiva foi elaborada num contexto de insegurança interna nos países da América Latina, onde forças revolucionárias estavam conquistando vitórias sobre as forças legais. Tal fato gerava grande impacto no mundo ocidental. 
InterAção | 167

co-militar ocidental; sem embargo, foi apenas com o "pragmatismo responsável" que os interesses nacionais foram priorizados, rejeitando o alinhamento automático com o Mundo Ocidental. (SOUTO MAIOR, 2000)

Essa discrepância entre as políticas adotadas em 1964 e 1974 é explicada em parte pela diferença econômica do Brasil nos dois períodos. As importações e as exportações dobraram e quadruplicaram, respectivamente, nesses dez anos. Além disso, assistiu-se uma grande diversificação da pauta de produtos exportados, com a participação do café caindo para 25\%, enquanto que as participações da soja e dos produtos manufaturados aumentaram consideravelmente. A expansão da industrialização transformou o país num concorrente de outros países industrializados, gerando atritos principalmente com os Estados Unidos e a Comunidade Europeia. Temos ainda o aumento da dívida externa, o que significava uma maior exposição brasileira frente ao jogo das forças econômicas internacionais. Em resumo, temos uma vigorosa alteração na inserção do Brasil na economia internacional, onde o choque de interesses entre países ricos e pobres corroborou para a mudança de postura do governo nacional. (SOUTO MAIOR, p. 441-442)

Outro fator relevante para explicar a divergência entre as políticas de Castello Branco e de Geisel é a alteração da conjuntura

Para combater as forças subversivas, o Brasil passou a advogar a defesa coletiva do continente americano, consubstanciada através da reestruturação da Organização dos Estados Americanos. Além de coletiva, a segurança seria integral, por abarcar todos os planos possíveis, seja político, econômico, militar ou ideológico. 
internacional. Durante os dez anos entre as duas gestões, houve um relativo abrandamento da guerra fria. A adoção de uma política de détente pelas duas superpotências contribuiu para o surgimento de um mundo multipolar, com muito mais alternativas de parceiros comerciais para o Brasil. Além disso, as possibilidades para tomada de empréstimo externo também aumentavam, tendo em vista o grande volume de capital disponível no mercado financeiro internacional e o seu interesse em reciclar os chamados petrodólares (PINHEIRO, 1993, p. 247-260). Os empréstimos externos constituíam a única forma de viabilizar o objetivo central do governo de manter o crescimento econômico acelerado.

Unindo-se a abundância no mercado financeiro ao aumento de protecionismo nos principais parceiros comerciais do país - especialmente nos Estados Unidos - teve-se a circunstância econômica ideal para a diversificação nas relações diplomático-comerciais. A linha política a ser perseguida pelo governo Geisel tinha então o respaldo necessário em vários pontos, consolidando, dentre as partes civis do governo, a percepção da necessidade da inflexão na política exterior brasileira.

As conjunturas interna e externa que deliniaram o ano de 1974 são, portanto, fatores que permitem a adoção de uma política externa de afirmação nacional como era o "pragmatismo responsável”. O conceito de pragmatismo se relacionava à eficiência material; à ideia de uma política descomprometida com princípios ideológicos que pudessem dificultar a consecução de interesses nacionais, que sugeria que o Brasil estava pronto para adaptar-se a qualquer mudança potencial no sistema internacional. $\mathrm{O}$ termo 
InterAção | 169

responsabilidade relacionava-se às questões ideológicas, que não deveriam contaminar a política externa; tratava-se de uma palavra-chave dirigida às bases de sustentação do regime militar. Diz-se ainda que a política externa de Geisel foi "ecumênica", devido ao caráter universalista de sua política externa, objetivando o incremento das relações internacionais do país. (VIZENTINI, 2004, p. 208; PINHEIRO, p. 249)

Talvez a grande constatação feita pelos elaboradores da política externa que viria a ser adotada em 1974 é a de que a ordem internacional vigente constituía um obstáculo para o desenvolvimento social e econômico dos países do chamado Terceiro Mundo. Assim, a aproximação do Brasil com os demais países pobres era necessária, sendo talvez a única estratégia disponível para alterar a ordem econômica mundial. Não obstante, essa aproximação não era um objetivo em si, pois havia a consciência de que os países ricos eram os únicos detentores de tecnologia e financiamentos tão necessários para a conquista do desenvolvimento no país. Com efeito, existia uma política de solidariedade com o Terceiro Mundo e de preferência econômica pelo Norte.

Assim, entre as características gerais da política externa adotada pelo governo de Geisel, merecem destaque o fim do apoio ao colonialismo português na África e a adoção de uma postura pró-árabe no conflito árabe-israelense. Merece menção também a atitude brasileira em fóruns multilaterais, reivindicadora de uma maior participação no sistema internacional. Tal prática reforçava as posições brasileiras nas negociações bilaterais com países desenvolvidos. (PINHEIRO, p. 250) 
170 | InterAção

\section{Precedentes históricos do Reconhecimento Diplomático}

O primeiro momento representativo da política externa brasileira em relação ao novo governo em Beijing se deu com a Guerra da Coreia, no início da década de 1950. O então governo Vargas, embora alinhado com os Estados Unidos, recusou o convite de enviar tropas à península asiática, evitando se comprometer com um lado em especial. Entretanto, é a partir do governo de Jânio Quadros que a relação com a RPC ganha importância no contexto da Política Externa Independente (PEI).

A partir de uma série de medidas que posteriormente seriam caracterizadas por Castello Branco como "práticas sinuosas", o presidente Jânio Quadros inicia uma aproximação com o governo de Mao Zedong, culminando no envio do vice-presidente João Goulart para Beijing em 1961. Na China Popular, um dos principais fatores da política externa do governo revolucionário de então era o cisma sino-soviético. Com a morte de Stalin e o revisionismo de Kruschev, os já existentes ressentimentos entre a China maoísta e a União Soviética se transformaram num afastamento completo entre os dois países socialistas, ideológica e politicamente. Assim, a RPC, tendo que contornar o crescente isolamento internacional, passou a investir no fomento de relações diplomáticas e comerciais com outros países subdesenvolvidos do chamado Terceiro Mundo. As relações bilaterais atingiam um ápice inédito quando os eventos de meados da década de 1960 impuseram um retrocesso na crescente aproximação entre os dois países.

Durante as duas primeiras décadas do governo comunista em 
InterAção | 171

Beijing, a revolução esteve muito presente na política externa da RPC. A exportação do ideário da revolução maoísta era preponderante nas iniciativas internacionais chinesas, principalmente após o cisma sino-soviético. Existia um conflito entre os dois modelos de revolução socialista, embora não fosse aberto e total, ao mesmo tempo em que imperava na América Latina a política de contenção praticada pelos Estados Unidos. O conhecimento do patrocínio chinês a partidos políticos na América Latina invariavelmente entrava em choque com as alas políticas conservadoras, já insatisfeitas com as práticas populistas do governo democrático de então.

Como fruto da alta polarização na política brasileira no contexto da queda de João Goulart, nove funcionários chineses que se encontravam no país, entre eles alguns encarregados de instalar um escritório comercial (previamente negociado entre o governo Jango e a RPC), foram presos sob a acusação de "conspirar contra a segurança nacional". Em grande parte iniciativa do governador da Guanabara, Carlos Lacerda, a prisão ia ao encontro das acusações de que a movimentação sindical, em particular as greves de 1963, havia sido organizada por inspiração maoísta (PINHEIRO). Tal evento encerra, no Brasil, o ciclo de aproximação bilateral. Comparativamente, na China também se observa nos meados da década de 1960 a ação das alas mais extremadas do Partido Comunista Chinês (PCCh) com a Revolução Cultural, encabeçada por Mao, que visava afastar as lideranças moderadas e acabou por mergulhar o país na turbulência política. Tais eventos se relacionam diretamente ao cenário internacional de alta polarização, agravado com a crise dos mísseis de Cuba de 1962 e a multiplicação de arsenais nucleares. 
172 | InterAção

A prisão dos representantes chineses, de teor político, caracteriza a arena decisória da política doméstica do período referido. Durante a era Castello Branco, ao contrário do que se percebe na era Geisel, as partes conservadoras - que naturalmente não aceitariam empreender esforços diplomáticos direcionados a uma nação socialista como a China Popular - têm voz ativa no gabinete presidencial e poder de veto nas decisões políticas. A isso também se deve as duas presidências seguintes, de Costa e Silva e Médici, militares ligados à "linha dura".

Com as mudanças do equilíbrio internacional do final da década de 1960, mudam também as conjunturas internas de Brasil e da RPC. A criação do TNP e a prática da détente entre as duas superpotências ditam um novo ambiente internacional, onde os dois países recomeçam a se identificar mutuamente e a reconstruir suas relações. A oposição à assinatura do TNP por ambos os países aproximam estes nos fori internacionais, enquanto a China continental se aproxima cada vez mais de países em desenvolvimento como o Brasil, dado o ressentimento com as doutrinas Nixon e Kruschev. Com as iniciativas norte-americanas em relação à reinserção da China comunista no cenário internacional, têm-se um episódio controverso: o Brasil nega a entrada da China continental na ONU. As críticas do então Ministro Gibson Barbosa (BECARD, 2008) refletem o descontentamento com o "clube do poder das potências ocidentais" que apoiaram a entrada da China puramente por questões de realismo político; ou seja, tendo por fim enfraquecer o rival-amistoso, a URSS.

Mas mais importantes foram as mudanças ideológicas nos governos brasileiro e chinês e na distribuição de poder interno. $\mathrm{Na}$ 
InterAção | 173

RPC, a Revolução Cultural começa a esmaecer com a percepção do cumprimento do objetivo, enquanto que o apoio americano fomenta a identificação com o Terceiro Mundo. A luta entre moderados (dentre os quais estava o futuro líder partidário Deng Xiaoping) e os extremados continuaria internamente até 1976, embora externamente já houvesse ali um grau de liberalização. Em 1972, a China apoia diplomaticamente o Chile de Pinochet na questão dos direitos humanos versus soberania, ponto que é percebido pelo governo militar brasileiro como muito favorável. O apoio ao Chile, que era um promissor parceiro econômico, juntamente com o apoio às pretensões territoriais marítimas de países da América Latina em relação ao território contestado pelos Estados Unidos, acaba por iniciar uma reversão da imagem negativa que o governo militar brasileiro tinha sobre a China de Mao.

\section{Pragmatismo Responsável, a Teoria dos Três Mundos e 0 Reatrela- mento com Beijing}

A década de 1970 é de grandes transformações internas no Brasil e na RPC. No Brasil, sobe ao poder um militar da área moderada depois de dois presidentes da linha dura. Na China, o grupo moderado, liderado por Deng Xiaoping, consegue ressuscitar politicamente e começa a reverter a balança de poder interna, culminando na queda do grupo que ficou conhecido como Bando dos Quatro, proeminente durante a revolução cultural. Também no cenário internacional se contemplam mudanças significativas. $\mathrm{O}$ choque do petróleo, a desvalorização do dólar e o mau desempenho econômico das potências ocidentais 
174 | InterAção

impõem uma nova realidade aos países exportadores de produtos primários no bloco ocidental, onde se encaixa o Brasil.

A questão para o Brasil era se existiam condições internas para a diversificação das parcerias internacionais para além das barreiras ideológicas, mesmo em um regime que se respaldava na questão ideológica. Com a ascensão do general Geisel e as consequentes mudanças no processo de decisão política, a resposta foi positiva. $\mathrm{O}$ pragmatismo responsável, colocado em prática por uma política externa "responsável e ecumênica", eliminava na medida do possível as barreiras ideológicas para a diplomacia do regime militar. Mas se sabe que havia forte oposição dentre os militares. Portanto, dificilmente o reconhecimento teria acontecido no tempo em que se deu, não fosse a atitude da liderança de Geisel e o enfraquecimento de certos órgãos do regime.

O processo de reaproximação com a China já estava em andamento, embora com pouca profundidade, desde o final da década de 1960, por iniciativa do Itamaraty. Mais especificamente, a iniciativa foi feita pela Divisão de Ásia e Oceania, encabeçada pelo conselheiro Carlos Antônio Bettencourt Bueno. O Ministério das Relações Exteriores manteve um acompanhamento constante do que acontecia na República Popular da China, o que lhe permitiu perceber o esmaecimento da Revolução Cultural e das novas possibilidades de parceria que o país asiático oferecia.

O Itamaraty consolida sua liderança em matéria de política externa na gestão Geisel-Azeredo da Silveira, Ministro das Relações Exteriores até a posse de Figueiredo. Como se observa no cronograma das missões e de outras iniciativas diplomáticas, a aplicação do 
pragmatismo responsável no reconhecimento diplomático da RPC foi uma decisão tomada unilateralmente pelo gabinete presidencial, em consulta e com o consentimento do Itamaraty. Quando a Secretaria Geral da Comissão de Segurança Nacional se pronunciou a respeito da questão, a iniciativa já havia sido tomada. ${ }^{2}$

Assim, o estilo autocrático da administração Geisel constituiu fator chave no reconhecimento da RPC. O governo acabou por ser muito mais um governo pessoal do que característico de "junta", como se observa frequentemente nos regimes militares. Não só isso, mas também a boa relação com o Itamaraty, que ganhava destaque dentre os órgãos informativos no plano da política externa, possibilitou a percepção das novas possibilidades oriundas das mudanças no sistema internacional e na dinâmica política interna chinesa. Uma vez percebido o novo quadro, era somente natural o curso de ação tomado, o que aconteceu apesar da falta de consenso entre os militares. Também se percebe a perda de espaço de outros órgãos de inteligência, em especial do SNI, que contava com participação direta nos gabinetes civil e militar, em matéria de política externa, durante o governo Médici.

De fato, a China transformava-se na década de 1970. Passados os piores anos da rixa entre Mao Zedong e Deng Xiaoping, o discurso na Assembleia Geral da ONU de Deng Xiaoping sobre a

2 Observando o calendário dos acontecimentos, percebe-se que a decisão já escolhida previamente foi só referendada pelo restante do governo, ainda assim sem consenso. 0s ministros militares - Exército, Marinha, etc. - se opuseram à proposta do presidente Geisel (PINHEIR0) 
176 | InterAção

Teoria dos Três Mundos³ , em 1974, sela um retorno das iniciativas internacionais em geral, com foco na relação Sul-Sul. Este tipo de relacionamento havia ficado em segundo plano durante a década de 1960, dado o foco exigido pelo conflito político interno. O Itamaraty acompanhava o processo com atenção, através dos chamados Relatórios de Hong-Kong (PINHEIRO), e a comunicação direta com o presidente da qual usufruía o MRE possibilitou que a ação apropriada fosse tomada.

Com efeito, após a chegada da delegação comercial chinesa em sete de agosto de 1974, o governo brasileiro fez pública a decisão, em 15 de agosto, do reconhecimento da China de Beijing, cristalizando as mudanças empreendidas com a presidência do General Geisel em relação aos presidentes militares anteriores. Tal atitude não poderia ter acontecido tão prontamente não fosse a nova dinâmica política no governo Geisel.

\section{CONSIDERAÇÕES FINAIS}

O primeiro aspecto a se ressaltar é a importância do momento interno vivido nos dois países durante as iniciativas de fomento das relações bilaterais. As circunstâncias internacionais favoráveis à aproximação comercial e diplomática entre novos parceiros já exis-

3 A Teoria dos Três Mundos chinesa difere da contrapartida ocidental, em que 0 $1^{\circ}$ Mundo é 0 capitalista desenvolvido, $02^{\circ}$ é 0 socialista e $03^{\circ}$ é composto pelas economias subdesenvolvidas. A Teoria chinesa se foca nas diferenças ideológicas e de poder: $01^{\circ}$ Mundo é composto pelas super-potências, $02^{\circ}$ é formado pelos seus aliados e $03^{\circ}$ seria formado pelos não-alinhados, onde se encontraria a RPC 
tiam desde o início da década, com a crise do petróleo consolidando o novo quadro. Entretanto, a cooperação que se deu exigia esforço diplomático e superposição ao poder de veto, no caso do Brasil, dos setores descontentes com a nova parceria. A política externa, embora combatesse esse poder, deveria ser gradual e, portanto, "responsável". Nota-se que:

“A implementação do projeto de política externa
do governo Geisel passou pela recomposição da
correlação de forças dentro da estrutura de poder.
Este projeto aparece como causa e efeito desta re-
composição, na medida em que se inclui no pacote
de políticas que, ao serem desenvolvidas concreta-
mente, agravam o nível de tensões e divergências no
próprio meio militar." (HIRST apud PINHEIRO)

As mudanças domésticas tiveram papel mais crítico no lado brasileiro do que no chinês, uma vez que foi o Brasil que havia interrompido o crescente das relações bilaterais com o início do regime militar em 1964. A contrapartida chinesa sempre se apresentou comprometida com a aproximação, que era barrada pelo lado brasileiro. Entretanto, a análise das mudanças chinesas não deve ser descartada, uma vez que, como aponta PINHEIRO, foi a percepção, por parte do Itamaraty, das mudanças no panorama político da China continental que acionou a série de iniciativas visando a reaproximação com Beijing. Como mais um exemplo da importância do cenário doméstico, observa-se que os primeiros anos da parceria foram de pouca transação comercial - foram os anos, na RPC, em que o poder ainda não havia sido consolidado pela facção em ascensão, liderada por Deng Xiaoping, que só consegue reverter de fato a situação em 1976. 
178 I InterAção

Destarte, em 1976, ano da queda do Bando dos Quatro na China, a corrente de comércio Brasil-China foi a mais baixa da história das relações diplomáticas formais entre os países. Já em 1977, ultrapassou a marca de US $\$ 150$ milhões. (BECARD)

Finalmente, percebe-se também a relação dos momentos políticos internos entre os dois países. $\mathrm{O}$ grau de semelhança no jogo entre moderados e exaltados dentro do novo regime, em ambos os países, deve-se em muito às semelhanças dos países e do seu papel no sistema internacional bipolar. Ambos de tamanho continental, com economias em vias de se desenvolver, Brasil e China sofriam as consequências do jogo entre as superpotências (respectivamente, EUA e URSS) de forma semelhante.

\section{REFERÊNCIAS}

BECARD, Danielly Silva Ramos .O Brasil e a República Popular da China: política externa comparada e relações bilaterais (1974-2004). Brasília, FUNAG, 2008.

BREDA DOS SANTOS, Norma. "O Brasil e a questão israelense nas Nações Unidas: da criação do Estado de Israel ao pós-sionismo". In: BREDA DOS SANTOS, Norma. Brasil e Israel: diplomacia e sociedades. Brasília: Editora Universidade de Brasília, 2000, p. 56.

D'ARAUJO, Maria Celina e CASTRO, Celso (org.). Ernesto Geisel. Rio de Janeiro: Editora Fundação Getulio Vargas, 1997, p. 335-360.

HIRST, Mônica. "Democratic transition and foreign policy; the experience of Brazil" in Latin American nations in world politics. Boulder, Colorado: Westview Press, 1984. 
MALAN, Pedro Sampaio. Relações Econômicas Internacionais do Brasil (1945-1964). In: FAUSTO, Bóris (org.). História Geral da Civilização Brasileira. São Paulo: Difel, 1984, p. 51-106.

MENEZZETTI, Fernando. De Mao a Deng: a transformação da China. Brasília: Edunb, 2000.

PINHEIRO, Letícia. O Restabelecimento de relações diplomáticas com a República popular da China. Estudos históricos. Vol 6, n 12, p. 247-273. 1993.

SOUTO MAIOR, Luiz Augusto. O Pragmatismo Responsável. In: ALBUQUERQUE, J. A. Guilhon (Org.). Sessenta Anos de Política Externa 1930-1990. São Paulo: ANNABLUME/NUPRI/USP, 2000, v. 1.

VIZENTINI, Paulo. G. F. A politica externa do Regime militar brasileiro. Porto Alegre: Ed.UFRGS, 1998.

VIZENTINI, Paulo Fagundes; RODRIGUES, Gabriela. O Dragão Chinês e os Tigres Asiáticos. Porto Alegre: Novo Século, 2000. 